\title{
Epitaxial Growth and Optically Pumped Stimulated Emission in AIGaN/InGaN Ultraviolet Multi-Quantum-Well Structures
}

\author{
PING CHEN @0, ${ }^{1,2,3}$ YOUNG JAE PARK, ${ }^{1}$ YUH-SHIUAN LIU, ${ }^{1}$ \\ THEERADETCH DETCHPROHM ${ }^{1}{ }^{1}$ P. DOUGLAS YODER,${ }^{1}$ \\ SHYH-CHIANG SHEN, ${ }^{1}$ and RUSSELL D. DUPUIS ${ }^{1,4}$
}

\begin{abstract}
1.-Center for Compound Semiconductors and School of Electrical and Computer Engineering, Georgia Institute of Technology, Atlanta, GA 30332-0250, USA. 2.-State Key Laboratory of Integrated Optoelectronics, Institute of Semiconductors, Chinese Academy of Sciences, Beijing 100083, China. 3.-Center of Materials Science and Optoelectronics Engineering, University of Chinese Academy of Sciences, Beijing 100049, China. 4.-e-mail: dupuis@gatech.edu
\end{abstract}

The thermal effect of the growth temperature on interface morphology and stimulated emission in ultraviolet $\mathrm{AlGaN} / \mathrm{InGaN}$ multiple quantum wells (MQWs) are experimentally investigated. During the MOCVD epitaxial growth of $\mathrm{AlGaN} / \mathrm{InGaN} \mathrm{MQWs}$, the ramping rate from a lower temperature for InGaN quantum wells (QWs) to a higher one for AlGaN quantum barriers $(\mathrm{QBs})$ is intentionally changed from $1.0^{\circ} \mathrm{C} / \mathrm{s}$ to $4.0^{\circ} \mathrm{C} / \mathrm{s}$. Atomic force microscopy images show that the surface morphology of InGaN QWs, which is improved by a thermal effect when the growth temperature rises to the set value of the AlGaN QBs, varies with different temperature ramping rates. The results of stimulated emission indicate that the threshold pumping power density of MQWs is decreased with increasing temperature ramping rate from $1.0^{\circ} \mathrm{C} / \mathrm{s}$ to $3.0^{\circ} \mathrm{C} / \mathrm{s}$ and then slightly increased when the ramping rate is $4.0^{\circ} \mathrm{C} /$ $\mathrm{s}$. This phenomenon is believed to result from the thermal degradation effect during the temperature ramp step. A long-time high-temperature annealing will reduce the density of indium-rich microstructures as well as the corresponding localized state density, which is assumed to contribute to the radiative recombination in the InGaN QWs. Given the great difference between optimal growth temperatures for AlGaN and InGaN layers, a higher ramping rate would be more appropriate for the growth of ultraviolet $\mathrm{AlGaN} /$ InGaN MQWs.

Key words: Metalorganic chemical vapor deposition (MOCVD), multiple-quantum-well (MQW), ultraviolet, stimulated emission, atomic force microscopy

\section{INTRODUCTION}

With the composition changes of indium or aluminum, the bandgap energy of the direct-bandgap III-nitrides alloys varies from $0.7 \mathrm{eV}$ for $\mathrm{InN}$ to $6.2 \mathrm{eV}$ for AlN continuously, covering the entire spectral range of visible light to far ultraviolet (UV) light. ${ }^{1-4}$ UV light emitting diodes (LEDs) and laser

(Received September 20, 2019; accepted December 27, 2019; published online January 8, 2020) diodes (LDs) are considered to be of great significance for a series of applications, for example, biomedical instruments, biochemical detection, and water purification. ${ }^{5-9}$ InGaN-based UV LEDs and LDs are normally grown on sapphire substrates using metalorganic chemical vapor deposition (MOCVD). However, there are several materials issues for III-N epitaxial films, such as a high defect density $\left(10^{8}-10^{10} \mathrm{~cm}^{-2}\right)$ and a large piezoelectric field due to the large lattice mismatch and the difference in thermal expansion coefficients between InGaN and (Al)GaN layers, resulting in 
the reduction of the internal quantum efficiency. AlGaN has been used as the quantum barriers (QBs) of InGaN quantum wells (QWs) for UV optoelectronic devices. ${ }^{10-14}$ Unfortunately, it is challenging to optimize the crystal quality of both the InGaN and AlGaN layers in the multiple quantum wells (MQWs), due to the lower growth temperatures and nitrogen environment required for InGaN. Moreover, there is a big difference in the optimal growth temperature between the InGaN and AlGaN layers, which could adversely affect material quality and device performance. The optimum growth temperature of $\mathrm{AlGaN} \mathrm{QBs}$ is much higher than that of InGaN QWs. The higher optimal growth temperature of $\mathrm{AlGaN} \mathrm{QBs}$ causes the thermal degradation and decomposition for InGaN QWs, resulting in reduction of radiative recombination rate in the MQWs active region. ${ }^{15-17}$ In order to suppress the negative influence of high growth temperature, we have investigated the effect of temperature ramping rate $\left(R_{\mathrm{t}}\right)$ at the ramp step from InGaN to AlGaN on the stimulated emission characteristics of ultraviolet $\mathrm{AlGaN} / \mathrm{InGaN}$ MQWs.

\section{EXPERIMENTS}

The epitaxial growth was performed in an AIXTRON $6 \times 2^{\prime \prime}$ close-coupled showerhead metalorganic chemical vapor deposition reactor system. Trimethylgallium $\left(\mathrm{Ga}\left(\mathrm{CH}_{3}\right)_{3}\right.$, TMGa), trimethylaluminum $\left(\mathrm{Al}\left(\mathrm{CH}_{3}\right)_{3}, \mathrm{TMAl}\right)$, and trimethylindium $\left(\operatorname{In}\left(\mathrm{CH}_{3}\right)_{3}\right.$, TMIn) were used for group III precursors while ammonia $\left(\mathrm{NH}_{3}\right)$ was used for the group $\mathrm{V}$ precursor. Figure 1 shows the schematic cross-sectional view of MQWs structures. The substrates employed in this study were sapphire substrates $430 \mu \mathrm{m}$ thick and $50 \mathrm{~mm}$ in diamater (0001). After the growth of a 20-nm low-temperature GaN buffer layer and a 3.5- $\mu \mathrm{m}$ unintentionally doped $\mathrm{GaN}$ layer, five pairs of $\mathrm{Al}_{0.12} \mathrm{Ga}_{0.88} \mathrm{~N}(7.0 \mathrm{~nm}) /$ $\mathrm{In}_{0.02} \mathrm{Ga}_{0.98} \mathrm{~N}(2.5 \mathrm{~nm}) \mathrm{MQW}$ structures were grown in $\mathrm{N}_{2}$ ambient with a growth pressure of $40 \mathrm{kPa}$. The substrate temperatures for AlGaN and InGaN were $940^{\circ} \mathrm{C}$ and $800^{\circ} \mathrm{C}$, respectively. Compared with the indium and gallium atoms, aluminum atoms have a lower surface mobility during migration. ${ }^{18-22}$ The growth temperature for $\mathrm{AlGaN} \mathrm{QBs}$ in our samples has been reduced to $940^{\circ} \mathrm{C}$ to suppress the

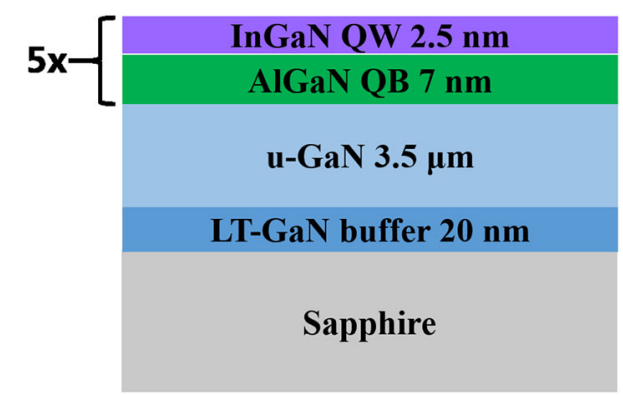

Fig. 1. Schematic diagram of $A I G a N / I n G a N ~ M Q W$ structure. expected thermal damage to InGaN QWs. At the same time, the growth rate of the $\mathrm{AlGaN}$ layer was also reduced to a value as low as $0.012 \mathrm{~nm} / \mathrm{s}$ to improve the surface morphology under this low temperature.

In order to investigate the effect of $R_{\mathrm{t}}$ on the surface morphology of InGaN, four types of MQWs with the last layer of InGaN were grown as shown in Fig. 1. The substrate temperature was elevated from $800^{\circ} \mathrm{C}$ to $940^{\circ} \mathrm{C}$ with various $R_{\mathrm{t}}$ for these four samples. The $R_{\mathrm{t}}$ during the temperature elevation was changed by controlling the value of ramp time. Then, the substrate temperature was lowered to the room temperature with $R_{\mathrm{t}}$ of $1.0^{\circ} \mathrm{C} / \mathrm{s}$. After the epitaxial growth in MOCVD, the surface morphologies of these samples were investigated by atomic force microscopy (AFM, Veeco 3100 SPM) measurement.

\section{RESULTS AND DISCUSSION}

The AFM images of MQWs with the top layer of InGaN but different $R_{\mathrm{t}}$ at the step of temperature elevation are shown in Fig. 2. Clear step-flow patterns with abrupt edges were observed. However, there are still some defects located near the edge of steps. From $5 \times 5 \mu \mathrm{m}^{2}$ AFM images, the defect density tends to increase with $R_{\mathrm{t}}$. The sample with ramping rate of $1.0^{\circ} \mathrm{C} / \mathrm{s}$ presents the surface morphology with the smallest defect density. When the rate increases from $1.0^{\circ} \mathrm{C} / \mathrm{s}$ to $3.0^{\circ} \mathrm{C} / \mathrm{s}$, the defect density gradually rises. For $1 \times 1 \mu \mathrm{m}^{2}$ AFM images, the measured areas were randomly selected with an increased uncertainty of surface appearance.

For the sample with $R_{\mathrm{t}}$ of $4.0^{\circ} \mathrm{C} / \mathrm{s}$, the surface morphology looks similar with that of $3.0^{\circ} \mathrm{C} / \mathrm{s}$. The reason is the practical limitation of heater in the MOCVD system. With such a higher ramping rate, growth temperature cannot increase from $800^{\circ} \mathrm{C}$ to $940^{\circ} \mathrm{C}$ within a very short time period. This process can be confirmed by the monitoring curves from the LayTec EpiTT system during MQWs growth. As a result, the two samples with $R_{\mathrm{t}}$ of $3.0^{\circ} \mathrm{C} / \mathrm{s}$ and $4.0^{\circ} \mathrm{C} /$ $\mathrm{s}$ have a similar surface morphology under AFM measurement.

After AFM characterization, the wafers were cleaved into Fabry-Perot laser bars and a resonance cavity was obtained. Input power-dependent photoluminescence (PL) measurements were carried out to investigate the stimulated emission characteristics of these samples. The laser bars were optically pumped at room temperature by an $\mathrm{ArF}$ excimer laser (Coherent Compex Pro110F, $\lambda_{\text {laser }}=193 \mathrm{~nm}$ ) with a pulse width of $20 \mathrm{~ns}$ at a repetition rate of $10 \mathrm{~Hz}$. The pumping light was injected from top surface of MQW structures, while optical amplification spectra and emitting light intensity was collected from facets by an Ocean Optics (Maya 2000Pro) fiber-connected spectrometer. ${ }^{12}$

Figure 3 shows the spectra of samples with a ramping rate of $3.0^{\circ} \mathrm{C} / \mathrm{s}$ while the pumping power 

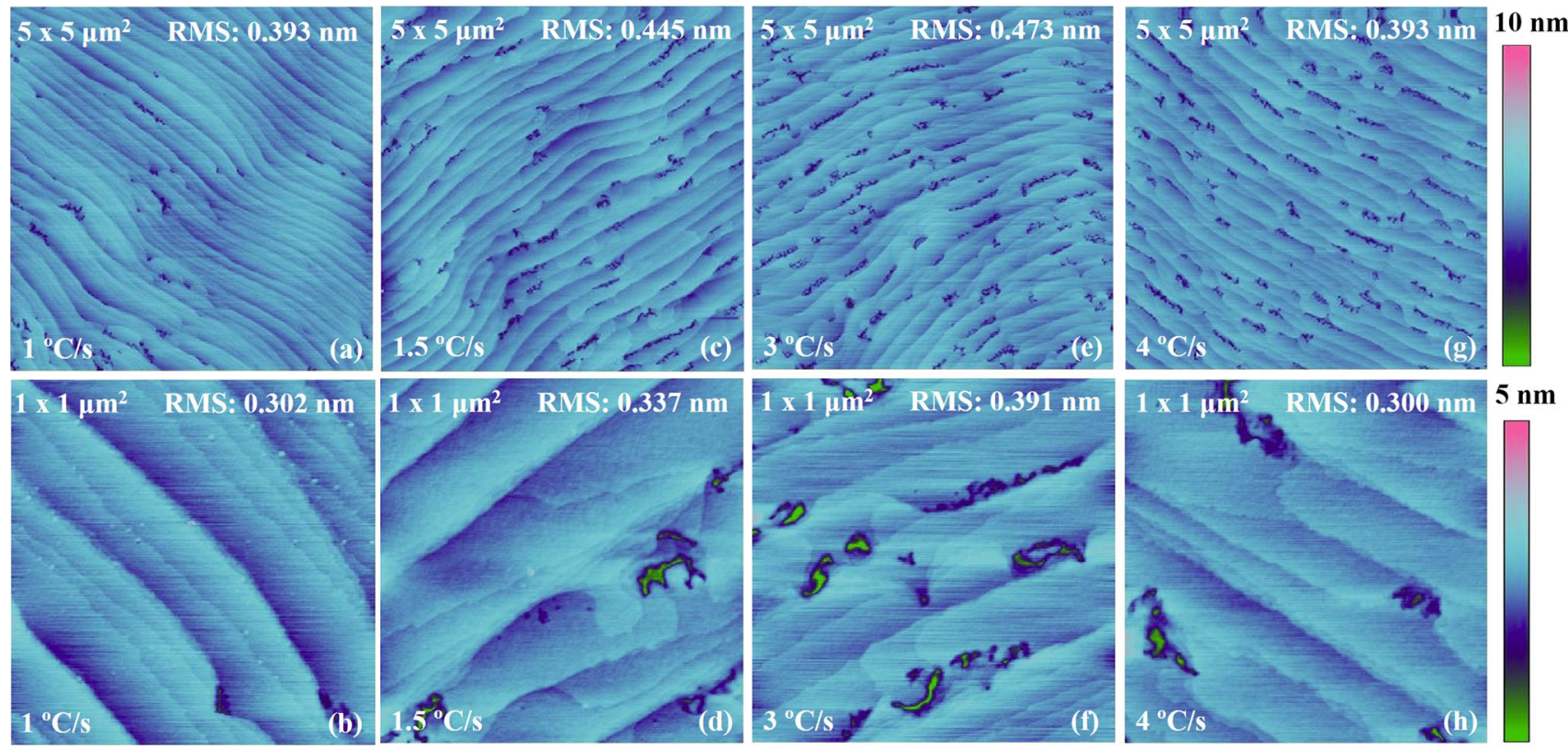

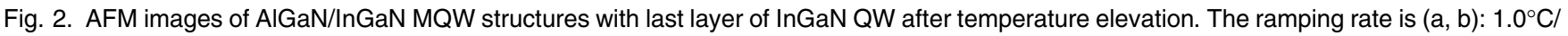
$\mathrm{s},(\mathrm{c}, \mathrm{d}): 1.5^{\circ} \mathrm{C} / \mathrm{s},(\mathrm{e}, \mathrm{f}): 3.0^{\circ} \mathrm{C} / \mathrm{s},(\mathrm{g}, \mathrm{h}): 4.0^{\circ} \mathrm{C} / \mathrm{s}$, respectively.

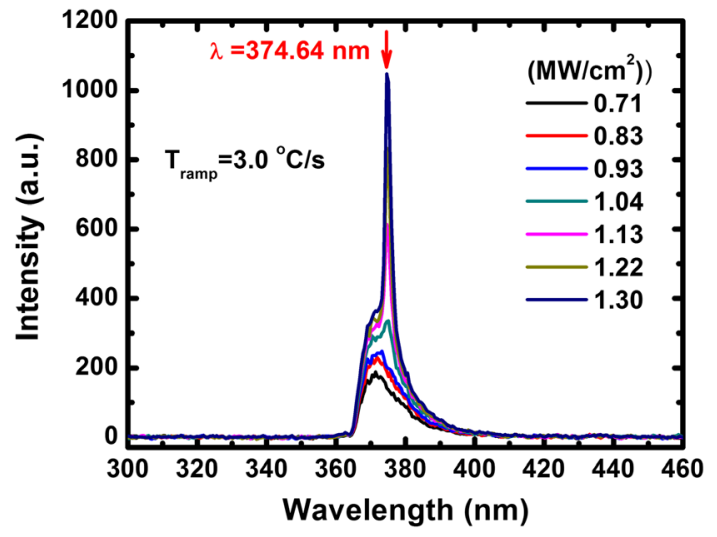

Fig. 3. Spectral curves of AIGaN/InGaN MQW structure with $R_{\mathrm{t}}$ of 3. $0^{\circ} \mathrm{C} / \mathrm{s}$ under an increasing optical pumping power.

density rises from $0.71 \mathrm{MW} / \mathrm{cm}^{2}$ to $1.30 \mathrm{MW} / \mathrm{cm}^{2}$. At low pumping power density of $0.71 \mathrm{MW} / \mathrm{cm}^{2}$, the photoluminescence spectra exhibited a relatively broad spontaneous emission peak at $373.3 \mathrm{~nm}$ with a full width at half maximum (FWHM) of $12.3 \mathrm{~nm}$. As the pumping power density approached $1.13 \mathrm{MW} / \mathrm{cm}^{2}$, a narrow peak emerged on the longer wavelength side. The peak developed into a sharp and strong emission with a peak wavelength of $374.64 \mathrm{~nm}$ under a pumping power density of $1.30 \mathrm{MW} / \mathrm{cm}^{2}$. A superlinear increase of stimulated light intensity was also observed beyond the threshold. At the same time, the FWHM of spectra peak dropped rapidly from $12.3 \mathrm{~nm}$ to $2.5 \mathrm{~nm}$. Changes in edge-emitted light intensity and FWHM values have been summarized and listed in Fig. 4. Given the adjustment of the fiber's position during the optical stimulation measurement for each sample, the values of the optical signal coupled into the spectrometer are different from one another. These data indicate a phenomenon of stimulated emission inside the cavity of AlGaN/InGaN MQW structures.

The values of threshold pumping power density for samples with various $R_{\mathrm{t}}$ are summarized and shown in Fig. 5c. It needs to be clarified that the values of threshold pumping power density for our samples are larger than those of full-laser-structure samples due to the lack of optical confinement structures such as waveguides or cladding layers. Figure 5c shows the threshold pumping power density of MQWs with $R_{\mathrm{t}}$ of $1.0^{\circ} \mathrm{C} / \mathrm{s}$ and $3.0^{\circ} \mathrm{C} / \mathrm{s}$ is $1.57 \mathrm{MW} / \mathrm{cm}^{2}$ and $1.24 \mathrm{MW} / \mathrm{cm}^{2}$, respectively, which has a $21 \%$ reduction with increasing $R_{\mathrm{t}}$. Then, it slightly increases to $1.36 \mathrm{MW} / \mathrm{cm}^{2}$ when $R_{\mathrm{t}}$ is $4.0^{\circ} \mathrm{C} / \mathrm{s}$. The lowest value of threshold pumping power density, which indicates the highest values of radiation recombination rate as well as internal quantum efficiency in $\mathrm{AlGaN} / \mathrm{InGaN}$ MQWs, can be obtained with the temperature ramping rate of $3.0^{\circ} \mathrm{C} / \mathrm{s}$.

To further examine the origin of the better lightemitting performance, surface morphology and photoluminescence spectral data are analyzed in more detail. The root-mean-square roughness $\left(R_{\mathrm{q}}\right)$ of $5 \times 5 \mu \mathrm{m}^{2}$ and $1 \times 1 \mu \mathrm{m}^{2}$ AFM images are plotted in Fig. 5a. $R_{\mathrm{q}}$ increases with $R_{\mathrm{t}}$ from $1.0^{\circ} \mathrm{C} / \mathrm{s}$ to $3.0^{\circ} \mathrm{C} / \mathrm{s}$, which indicates the surface gets degraded. When $R_{\mathrm{t}}$ increases from $3.0^{\circ} \mathrm{C} / \mathrm{s}$ to $4.0^{\circ} \mathrm{C} / \mathrm{s}, R_{\mathrm{q}}$ is decreased. This variation tendency of surface morphology is the result of the thermal effect during the temperature ramping step. Indium-rich microstructures exist both inside and on the surface of InGaN layers due to indium phase separation. ${ }^{17}$ When the growth temperature rises from $800^{\circ} \mathrm{C}$ to $940^{\circ} \mathrm{C}$, the 

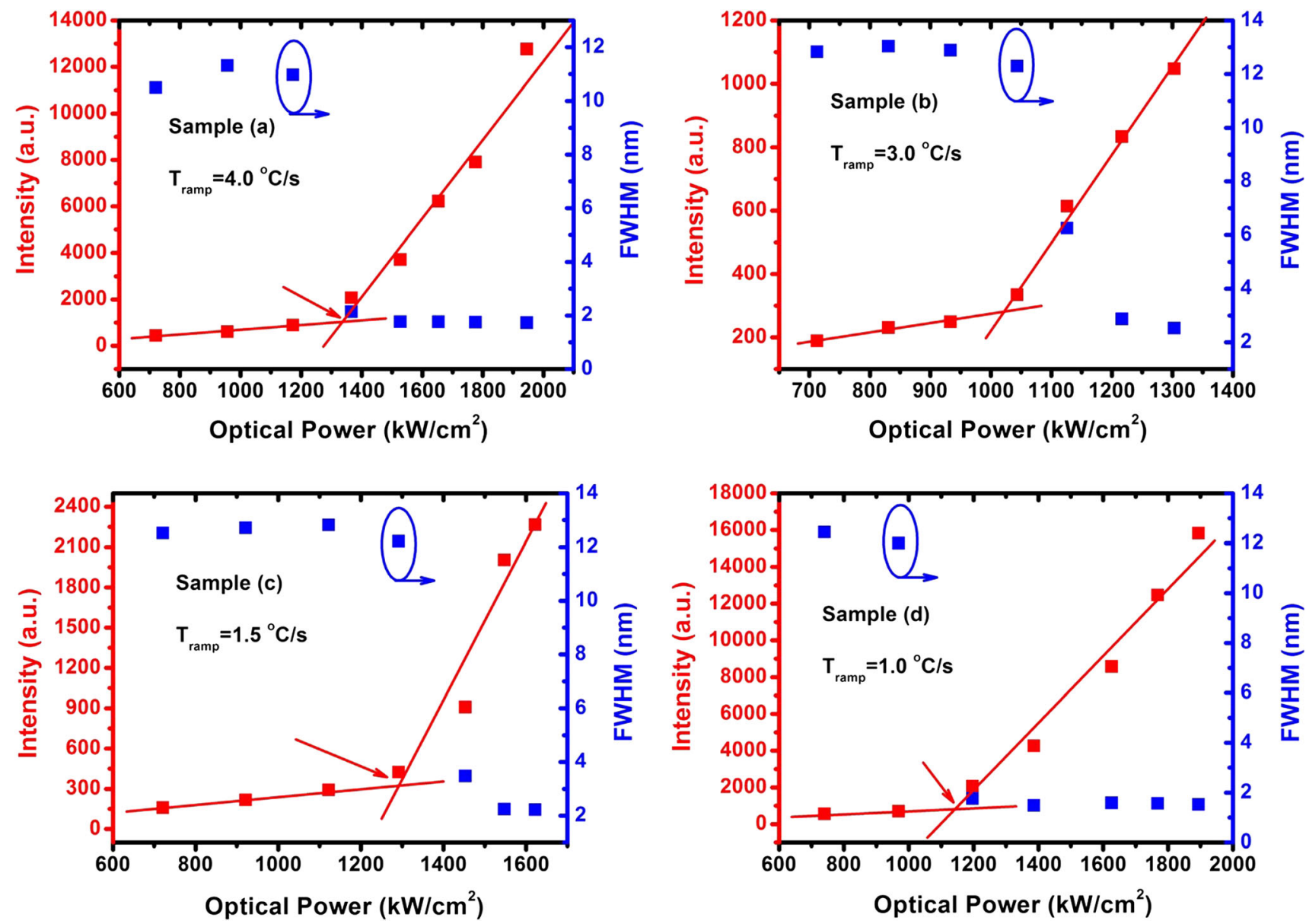

Fig. 4. Optical stimulated intensity (red) and FWHM (blue) of AIGaN/InGaN MQW structures under various optical pumping power (Color figure online).
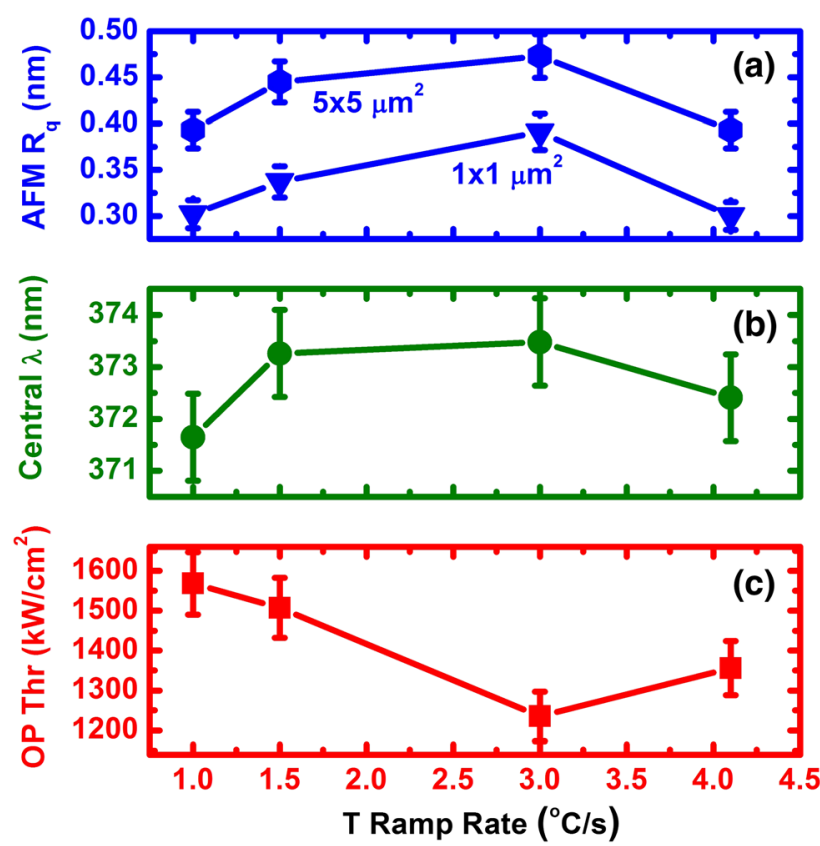

Fig. 5. Changes in the relationship between temperature ramping rate and (a) AFM surface roughness $R_{\mathrm{q}}$, (b) central spectral wavelength, and (c) threshold pumping power density.
InGaN surface is thermally annealed and the indium-rich areas are evaporated. Thus, the surface morphology becomes better with a longer ramping time. As a result, the sample with a higher $R_{\mathrm{t}}$ is accompanied by a lower surface roughness.

An abrupt interface in MQWs is considered to be beneficial to radiative recombination rate, as the density of non-radiation recombination centers near the interface has been reduced. However, an inappropriate thermal evaporation process of InGaN layer adversely affects the internal quantum efficiency. In case of an excessive high temperature or a long thermal annealing time, the indium-rich microstructures inside InGaN layers will decompose and indium component will diffuse out onto the surface. Thus, the localized state density in InGaN QWs, which is considered to contribute to increased internal quantum efficiency, is supposed to be lowered. $23-31$

In order to verify the indium composition variation in InGaN QWs, four samples of AlGaN/InGaN MQWs were measured for photoluminescence characteristics. The pumping power density of $\mathrm{ArF}$ excimer light source was set to be a fixed value much lower than their threshold power density, which is $0.7 \mathrm{MW} / \mathrm{cm}^{2}$ in this case. The central 
wavelength of PL spectra was extracted as shown in Fig. 5b. The central wavelength increases with ramping rate from $1.0^{\circ} \mathrm{C} / \mathrm{s}$ to $3.0^{\circ} \mathrm{C} / \mathrm{s}$, resulting from the rise of average indium composition inside InGaN QWs. It can be inferred that the indiumrich microstructures have partially decomposed under a longer temperature-ramp time. As the indium-rich microstructures can screen high-density defects or dislocations in InGaN layers, resulting in contributions to increased radiative recombination for AlGaN/InGaN MQWs, the ramping time from InGaN QWs to AlGaN QBs needs to be shortened to reduce negative influence of thermal effect. Consequently, the lowest threshold pumping power density is obtained under a ramping rate of $3.0^{\circ} \mathrm{C} / \mathrm{s}$, even though its surface morphology is not the smoothest in this situation.

Because of the practical limitation of an electrical resistance-wire heater in our MOCVD system, the growth temperature cannot reach the set value of AlGaN QBs when the ramping time is too short. During the practical growth of $\mathrm{AlGaN} / \mathrm{InGaN}$ MQWs with $R_{\mathrm{t}}$ of $4.0^{\circ} \mathrm{C} / \mathrm{s}$, the AlGaN crystal quality of the first few atomic layers is not high enough as the actual growth temperature is lower than the set value. The interface and energy barrier profile between InGaN QWs and AlGaN QBs are not as abrupt as in the sample with $R_{\mathrm{t}}$ of $3.0^{\circ} \mathrm{C} / \mathrm{s}$, resulting in a slightly larger value of threshold pumping power density for $\mathrm{MQWs}$ with $R_{\mathrm{t}}$ of $4.0^{\circ} \mathrm{C} / \mathrm{s}$. The limitation of the ramp rates generally exists in the heater control configuration of the MOCVD system. The heating curve is set to be linear and the temperature increases gradually to the set point. Thus, the temperature uniformity on the surface of the susceptor can be guaranteed while the unexpected damage of the heater can be avoided. The temperature profile needs to be designed and improved based on the limitation of the system setup.

\section{CONCLUSION}

In conclusion, the thermal effect during temperature elevation from InGaN to $\mathrm{AlGaN}$ on the interface morphology and stimulated emission performance was investigated for AlGaN/InGaN ultraviolet MQW structures. Four MQWs samples were grown with $R_{\mathrm{t}}$ from $1.0^{\circ} \mathrm{C} / \mathrm{s}$ to $4.0^{\circ} \mathrm{C} / \mathrm{s}$. The $A F M$ measurements showed a surface morphology of clear atomic step-flow patterns for InGaN QW layer. Surface roughness $R_{\mathrm{q}}$ in AFM measurement increased with $R_{\mathrm{t}}$ from $1.0^{\circ} \mathrm{C} / \mathrm{s}$ to $3.0^{\circ} \mathrm{C} / \mathrm{s}$ due to a lower thermal effect, which evaporated the indiumrich microstructures on surface of the InGaN layers. The stimulated emission was observed for the MQW samples with corresponding phenomena of superlinear enhancement of the emitted light intensity as well as the FWHM narrowing of the spectral peak. The values of threshold pumping power density decreased with increasing $R_{\mathrm{t}}$ from $1.0^{\circ} \mathrm{C} / \mathrm{s}$ to $3.0^{\circ} \mathrm{C} / \mathrm{s}$ due to an appropriate temperature ramp step and a corresponding suppressed high-temperature thermal degeneration of indium-rich microstructures inside InGaN layers. The variation of the indium composition inside the InGaN QWs was verified by analysis of the $300 \mathrm{~K} \mathrm{PL}$ spectra under a pumping power density lower than threshold value. Based on the experimental data, a higher $R_{\mathrm{t}}$ will be beneficial to the reduction of the negative effect of thermal degradation on radiative recombination rate in InGaN layers. A shorter time between growth temperatures ramping from InGaN to $\mathrm{AlGaN}$ is better to obtain the ultraviolet $\mathrm{AlGaN} / \mathrm{InGaN}$ MQWs with a higher internal quantum efficiency.

\section{ACKNOWLEDGMENTS}

This work is partially supported by the US Defense Advanced Research Projects Agency, the Steve W. Chaddick Endowed Chair in Electro-Optics, the Georgia Research Alliance, and the National Natural Science Foundation of China (61674139). This work was performed in part at the Georgia Tech Institute for Electronics and Nanotechnology, a member of the National Nanotechnology Coordinated Infrastructure (NNCI), which is supported by the National Science Foundation (Grant ECCS-1542174).

\section{OPEN ACCESS}

This article is licensed under a Creative Commons Attribution 4.0 International License, which permits use, sharing, adaptation, distribution and reproduction in any medium or format, as long as you give appropriate credit to the original author(s) and the source, provide a link to the Creative Commons licence, and indicate if changes were made. The images or other third party material in this article are included in the article's Creative Commons licence, unless indicated otherwise in a credit line to the material. If material is not included in the article's Creative Commons licence and your intended use is not permitted by statutory regulation or exceeds the permitted use, you will need to obtain permission directly from the copyright holder. To view a copy of this licence, visit http://creativecom mons.org/licenses/by/4.0/.

\section{REFERENCES}

1. I. Akasaki and H. Amano, Jpn. J. Appl. Phys. 36, 5393 (1997).

2. R.D. Dupuis and M.R. Krames, IEEE J. Lightwave Technol. 26, 1154 (2008).

3. M.T. Hardy, D.F. Feezell, S.P. DenBaars, and S. Nakamura, Mater. Today 14, 408 (2011).

4. M. Razeghi, IEEE Photonics J. 3, 263 (2011).

5. I. Akasaki, S. Sota, H. Sakai, T. Tanaka, M. Koike, and H. Amano, Electron. Lett. 32, 1105 (1996).

6. Y. Taniyasu, M. Kasu, and T. Makimoto, Nature 441, 325 (2006).

7. A. Khan, K. Balakrishnan, and T. Katona, Nat. Photonics 2, 77 (2008). 
8. M. Kneissl, T. Kolbe, C. Chua, V. Kueller, N. Lobo, J. Stellmach, A. Knauer, H. Rodriguez, S. Einfeldt, Z. Yang, N.M. Johnson, and M. Weyers, Semicond. Sci. Technol. 26 , 014036 (2011).

9. D.G. Zhao, J. Yang, Z.S. Liu, P. Chen, J.J. Zhu, D.S. Jiang, Y.S. Shi, H. Wang, L.H. Duan, L.Q. Zhang, and H. Yang, J. Semicond. 38, 051001 (2017).

10. S.H. Baek, J.H. Kim, M.K. Kwon, I.K. Park, S.I. Na, J.Y. Kim, B.J. Kim, and S.J. Park, IEEE Photonics Technol. Lett. 18,1276 (2006).

11. A. Knauer, H. Wenzel, T. Kolbe, S. Einfeldt, M. Weyers, M. Kneissl, and G. Tränkle, Appl. Phys. Lett. 92, 191912 (2008)

12. Y.-S. Liu, A.F.M.S. Haq, K. Mehta, T.-T. Kao, S. Wang, H.E. Xie, S.-C. Shen, P.D. Yoder, F.A. Ponce, T. Detchprohm, and R.D. Dupuis, Appl. Phys. Express 9, 111002 (2016).

13. K. Mehta, Y.-S. Liu, J.L. Wang, H. Jeong, T. Detchprohm, Y.J. Park, S.R. Alugubelli, S. Wang, F.A. Ponce, S.-C. Shen, R.D. Dupuis, and P.D. Yoder, IEEE J. Quantum Electron. 54, 2400507 (2018).

14. M.X. Feng, Z.C. Li, J. Wang, R. Zhou, Q. Sun, X.J. Sun, D.B. Li, H.W. Gao, Y. Zhou, S.M. Zhang, D.Y. Li, L.Q. Zhang, J.P. Li, H.B. Wang, M. Ikeda, X.H. Zheng, and H. Yang, ACS Photonics 5, 699 (2018).

15. Y.T. Moon, D.J. Kim, K.M. Song, C.J. Choi, S.H. Han, T.Y. Seong, and S.J. Park, J. Appl. Phys. 89, 6514 (2001).

16. J.Z. Hu, L.Q. Yang, and M.W. Shin, J. Phys. D Appl. Phys. 41, 035107 (2008).

17. Z.C. Li, J.P. Liu, M.X. Feng, K. Zhou, S.M. Zhang, H. Wang, D.Y. Li, L.Q. Zhang, D.G. Zhao, D.S. Jiang, H.B. Wang, and H. Yang, Appl. Phys. Lett. 103, 152109 (2013).

18. S. Ruffenach-Clur, O. Briot, J.L. Rouvière, B. Gil, and R.L. Aulombard, Mater. Sci. Eng. B 50, 219 (1997).

19. J.C. Rojo, L.J. Schowalter, R. Gaska, M. Shur, M.A. Khan, J. Yang, and D.D. Koleske, J. Cryst. Growth 240, 508 (2002).

20. M. Takeuchi, H. Shimizu, R. Kajitani, K. Kawasaki, T. Kinoshita, K. Takada, H. Murakami, Y. Kumagai, A. Koukitu,
T. Koyama, S.F. Chichibu, and Y. Aoyagi, J. Cryst. Growth 305, 360 (2007).

21. D.G. Zhao, D.S. Jiang, L.L. Wu, L.C. Le, L. Li, P. Chen, Z.S. Liu, J.J. Zhu, H. Wang, S.M. Zhang, and H. Yang, J. Alloys Compd. 544, 94 (2012).

22. X.H. Li, Y.O. Wei, S. Wang, H.E. Xie, T.-T. Kao, M.M. Satter, S.-C. Shen, P.D. Yoder, T. Detchprohm, R.D. Dupuis, A.M. Fischer, and F.A. Ponce, J. Cryst. Growth 414, 76 (2015).

23. S. Chichibu, T. Azuhata, T. Sota, and S. Nakamura, Appl. Phys. Lett. 70, 2822 (1997).

24. Y. Narukawa, Y. Kawakami, M. Funato, S. Fujita, S. Fujita, and S. Nakamura, Appl. Phys. Lett. 70, 981 (1997).

25. H. Hirayama, S. Tanaka, P. Ramvall, and Y. Aoyagi, Appl. Phys. Lett. 72, 1736 (1998).

26. R.A. Oliver, S.E. Bennett, T. Zhu, D.J. Beesley, M.J. Kappers, D.W. Saxey, A. Cerezo, and C.J. Humphreys, J. Phys. D Appl. Phys. 43, 354003 (2010).

27. D.G. Zhao, D.S. Jiang, L.C. Le, L.L. Wu, L. Li, J.J. Zhu, H. Wang, Z.S. Liu, S.M. Zhang, Q.J. Jia, and H. Yang, J. Alloys Compd. 540, 46 (2012).

28. C.-H. Lu, Y.-C. Li, Y.-H. Chen, S.-C. Tsai, Y.-L. Lai, Y.-L. Li, and C.-P. Liu, J. Alloys Compd. 555, 250 (2013).

29. H. Jeong, H.J. Jeong, H.M. Oh, C.-H. Hong, E.-K. Suh, G. Lerondel, and M.S. Jeong, Sci. Rep. 5, 9373 (2015).

30. J. Yang, D.G. Zhao, D.S. Jiang, P. Chen, J.J. Zhu, Z.S. Liu, J.P. Liu, L.Q. Zhang, H. Yang, Y.T. Zhang, and G.T. Du, J. Alloys Compd. 681, 522 (2016).

31. Y. Xing, D.G. Zhao, D.S. Jiang, Z.S. Liu, J.J. Zhu, P. Chen, J. Yang, W. Liu, F. Liang, S.T. Liu, L.Q. Zhang, W.J. Wang, M. Li, Y.T. Zhang, and G.T. Du, Superlattices Microstruct. 117,228 (2018).

Publisher's Note Springer Nature remains neutral with regard to jurisdictional claims in published maps and institutional affiliations. 